\title{
PRÁTICAS PEDAGÓGICAS DE ACOLHIMENTO E INCLUSÃO: A PERSPECTIVA DA PEDAGOGIA CRÍTICA
}

\author{
PRÁCTICAS PEDAGÓGICAS DE ACOGIDA E INCLUSIÓN: LA \\ PERSPECTIVA DE LA PEDAGOGÍA CRÍTICA
}

\section{PEDAGOGICAL PRACTICES OF RECEPTION AND INCLUSION: THE PERSPECTIVE OF CRITICAL PEDAGOGY}

\author{
Maria Amélia Santoro FRANCO ${ }^{1}$
}

\begin{abstract}
RESUMO: O presente artigo realça as possibilidades da pedagogia crítica na organização de práticas para inclusão e acolhimento dos alunos. Parte do pressuposto de que os princípios epistemológicos da pedagogia, na perspectiva crítica, contemplam as bases dos necessários processos de inclusão, para além do mero acolhimento, reafirmando que, numa sociedade de relações contraditórias, excludentes, desiguais, opressivas, a Pedagogia há que se fazer emancipatória, na continua busca de mais humanidade nos homens, o que se fará por meio da transformação das condições que produzem exclusão/opressão. Parte da seguinte questão de pesquisa: qual o sentido pedagógico das práticas de inclusão? Que contribuições a pedagogia crítica traz a essas práticas de inclusão e acolhimento? A pesquisa em pauta baseia-se em acompanhamentos de pesquisas-ações realizadas em três municípios do Brasil, com foco na inclusão de alunos carentes e também, em estudos teóricos dos sentidos da pedagogia, das práticas pedagógicas e da epistemologia da pedagogia crítica.
\end{abstract}

PALAVRAS-CHAVE: Práticas pedagógicas. Inclusão. Pedagogia crítica.

RESUMEN: El presente artículo subraya las posibilidades de la pedagogía crítica en la organización de prácticas para la inclusión y acogida de los alumnos. El trabajo parte del supuesto de que los principios epistemológicos de la pedagogía, en la perspectiva crítica, contemplan las bases de los necesarios procesos de inclusión, además de la mera acogida, reafirmando que, en una sociedad de relaciones contradictorias, excluyentes, desiguales, opresivas, la Pedagogía debe Se hace emancipatoria, en la continua búsqueda de más humanidad en los hombres, lo que se hará por medio de la transformación de las condiciones que producen exclusión I opresión. Dos cuestiones orientan la investigación: ¿cuál es el sentido pedagógico de las prácticas de inclusión? ¿Qué contribuciones la pedagogía crítica trae a esas prácticas de inclusión y acogida? La investigación en pauta se basa en acompañamientos de investigaciones-acciones realizadas en tres municipios de Brasil, con foco en la inclusión de alumnos carentes y también en estudios teóricos de los sentidos de la pedagogía, de las prácticas pedagógicas y de la epistemología de la pedagogía crítica.

${ }^{1}$ Universidade Católica de Santos (UCS), Santos, SP - Brasil. Docente e Pesquisadora CNPq. Doutora em Educação e Pós-doutorado em Pedagogia. E-mail: ameliasantoro@uol.com.br.

RPGE- Revista on line de Política e Gestão Educacional, Araraquara, v.21, n. esp.2, p. 964-978, nov. 2017. ISSN: $1519-9029$ 
PALABRAS CLAVE: Prácticas pedagógicas. Inclusión. Pedagogía crítica.

ABSTRACT: This article highlights the possibilities of critical pedagogy in the organization of practices for inclusion and acceptance of students. It is based on the assumption that the epistemological principles of pedagogy, in the critical perspective, contemplate the bases of the necessary processes of inclusion, beyond mere acceptance, reaffirming that in a society of contradictory, exclusionary, unequal, oppressive relationships, the practice of Pedagogy must have an emancipatory form, in the continuous search for more humanity in men, what will be done through the transformation of the conditions that produce exclusion / oppression. Part of the following research question: what is the pedagogical meaning of inclusion practices? What contributions does critical pedagogy bring to these inclusion and welcoming practices? The current research is based on the follow-up of actions researches carried out in three municipalities in Brazil, focusing on the inclusion of popular students and also on theoretical studies of the meanings of pedagogy, pedagogical practices and the epistemology of critical pedagogy.

KEYWORDS: Pedagogical practices. Inclusion. Critical pedagogy.

\section{Introdução}

Considero que as práticas pedagógicas de acolhimento e de inclusão são práticas inerentes à especificidade do trabalho pedagógico. Trabalhar pedagogicamente a docência implica sobretudo, um trabalho coletivo, democrático e que tem por finalidade a formação plena e integral de cada sujeito que participa do grupo, pressupondo assim, sua integração, sua convivência saudável e sua participação neste grupo em igualdade de condições com todos os participantes.

A condição pedagógica preconiza a inclusão e o acolhimento de todos os alunos, independentemente de suas especificidades físicas, intelectuais, sociais afetivas. Afinal, somos todos únicos, portanto, sempre diferentes entre nós. Como nascemos todos inacabados estamos continuamente caminhando em movimentos de vida e formação, em permanente processo de incorporação de novos acolhimentos e de novas inclusões.

Acredito que a pedagogia crítica, implícita nos pressupostos epistemológicos da pedagogia dos oprimidos proposta por Paulo Freire, oferece toda dimensão desta perspectiva que quero realçar neste artigo. Pretendo neste texto responder às questões: qual o sentido pedagógico das práticas de inclusão? Que contribuições a pedagogia crítica traz à essas práticas de inclusão e acolhimento? Acolher e incluir são práticas complementares ou práticas independentes? 
Para escrever este artigo respaldo-me em pesquisas participativas em escolas públicas, especialmente no período em que estive como diretora de escola estadual paulista; respaldo-me em acompanhamentos de pesquisas-ações em vários municípios do Brasil, com foco na inclusão de alunos carentes e também, em estudos teóricos dos sentidos da pedagogia, das práticas pedagógicas e da epistemologia da pedagogia crítica.

Parto ainda do pressuposto de que as práticas docentes reverberam as concepções de pedagogia que as sustentam, assim, o que afirmo faz sentido na perspectiva de uma pedagogia crítica que considera, entre outros pressupostos, que:

a)A finalidade da educação é formar sujeitos conscientes de seu lugar no mundo; sujeitos que, no processo educativo aprendem a dar nome e sentido ao mundo; jamais sujeitos despersonalizados e objetos à mercê de um processo que lhe é estranho;

b)A educação será sempre um ato de resistência à racionalização da prática educativa como pretexto de potencializar o desenvolvimento econômico; a educação em seu sentido latente, jamais poderá se concretizar na perspectiva mercadológica;

c)A construção do conhecimento se fará na prática dialógica; na vivência crítica da tensão entre teoria e prática e jamais se concretizará como transmissão de informações sem vinculação à realidade dos educandos ou dos educadores;

d)A emancipação dos sujeitos da prática deve organizar toda prática pedagógica, num processo contínuo de luta e compromisso social, onde se tecem os fundamentos de uma prática democrática e crítica. Esse processo não se fará, jamais, na perspectiva da doutrinação/domesticação dos sujeitos.

\section{A docência como prática inclusiva}

Tomo aqui de base uma frase dita por José Pacheco, numa de suas múltiplas palestras onde realça os fundamentos da Escola da Ponte: De repente percebi que dando aulas eu estava a excluir gente! Essa questão é fundamental: a docência precisa ser 
inclusiva! Faz parte de sua especificidade. No entanto, essa docência não pode ser meramente acolhedora, aquela docência que apenas acolhe as dificuldades postas pelo aluno e não o habilita a inserir-se como sujeito que sabe, que pode aprender e que aprende. Um sujeito autônomo e responsável! Um sujeito capaz de realizar suas potencialidades.

Repito a frase contundente de Pacheco: De repente percebi que dando aulas estava a excluir gente!

Quantos de nós, docentes em qualquer nível de ensino, já não chegou a pensar desta forma: como minha docência tem incluído ou excluídos alunos?

Acredito que grandes equívocos se construíram na ingênua prática pedagógica docente que tinha por base, apenas o bom intuito de acolher os alunos, sem recorrer à necessária aprendizagem que lhes era sugerida: acolher sim, no entanto incluí-los também no processo de crescimento, formação e aprendizagem. Lembro-me da voz de uma professora, de uma escola pública, da periferia de uma das grandes cidades do Brasil: coitadinho dele, meu aluno José, que só gosta de brincar na aula; como vou exigir dele alguma coisa, já que a vida é tão dura para ele! Deixa ele assim, não precisa aprender a escrever agora, a vida dará um jeito!

Considero ser este um grande equívoco! A docência, a prática educativa escolar, não pode ser mais um motivo de exclusão na vida de José. E também nisto Paulo Freire nos ajuda a pensar ao afirmar a responsabilidade social do fazer docente, que deve perpassar a mera acolhida afetiva. Ele assim se manifesta:

$\mathrm{O}$ fato, porém, de que ensinar ensina o ensinante a ensinar um certo conteúdo não deve significar, de modo algum, que o ensinante se aventure a ensinar sem competência para fazê-lo. Não o autoriza a ensinar o que não sabe. A responsabilidade ética, política e profissional do ensinante lhe coloca o dever de se preparar, de se capacitar, de se formar antes mesmo de iniciar sua atividade docente. Esta atividade exige que sua preparação, sua capacitação, sua formação, se tornem processos permanentes. Sua experiência docente, se bem percebida e bem vivida, vai deixando claro que ela requer uma formação permanente do ensinante. Formação que se funda na análise crítica de sua prática. ${ }^{2}$

Percebe-se a preocupação de Freire com a necessária formação do professor, de modo à superar a concepção ingênua de sua prática, uma vez que incluir o aluno no processo de curiosidade epistemológica de aprender, requer mais que acolher o aluno. É preciso método, didática e pedagogia, de forma que o aluno seja convidado à pensar

${ }^{2}$ Carta de Paulo Freire aos professores. Estud. Av., São Paulo, v. 15, n. 42, maio/ago.2001. 
além de suas condições atuais; é preciso que o convite ao aprendizado o insira nas práticas coletivas da sala de aula. A docência inclusiva implica a prática da relação dialógico-problematizadora, que ajuda a superar, por incorporação, os saberes do sensocomum trazidos por ambos, alunos e professores, o que requer a autonomia intelectual do docente. Há que se recordar, conforme Contreras (1994), que a autonomia docente não é uma qualidade presente individualmente em cada sujeito, mas um processo que vai, gradativamente, garantindo a assunção, por parte do professor, de sua responsabilidade social pela condução do ensino em situações complexas, historicamente construídas e ideologicamente comprometidas. Isso só pode ser feito com um sujeito que se sinta, se aperceba como ator de sua história, um sujeito empoderado, habilitado ao exercício do poder que advém de sua práxis. Esse é o grande desafio para uma docência inclusiva: autonomia, conhecimento e empoderamento do próprio professor. $\mathbf{E}$ é na conquista destas condições de trabalho docente que se inicia o processo de inclusão dos alunos. Será preciso, que antes de tudo, o professor sinta-se incluído em condições adequadas de profissionalização, de vida e formação.

\section{Práticas Pedagógicas}

A prática pedagógica que construo em meu espaço de trabalho docente tem condições de incluir os alunos? Gosto de fazer a análise da complexidade da prática, de forma que o professor perceba seu papel neste espaço.

É comum considerar que práticas pedagógicas e práticas educativas sejam palavras sinônimas e, portanto, unívocas. No entanto, ao falarmos de práticas educativas, estamos nos referindo à práticas que ocorrem para a concretização de processos educacionais. Já ao nos referirmos às práticas pedagógicas, estamos nos reportando à práticas sociais que se exercem com a finalidade de concretizar processos pedagógicos. Falamos, então, de práticas da Educação e práticas da Pedagogia. Mas, Pedagogia e Educação são conceitos e práticas distintas?

Trata-se, a meu ver, de conceitos mutuamente articulados, no entanto, com especificidades diferentes. Pode-se afirmar que a educação, numa perspectiva epistemológica, é o objeto de estudo da Pedagogia, enquanto que, numa perspectiva ontológica, é vista como um conjunto de práticas sociais que atuam e influenciam a vida dos sujeitos, de modo amplo, difuso e imprevisível. Por sua vez, a Pedagogia pode ser considerada como uma prática social que procura organizar/compreender/transformar as 
práticas sociais educativas que dão sentido e direção às práticas educacionais. Digamos que a Pedagogia impõe um filtro de significado à multiplicidade de práticas que ocorrem na vida das pessoas. A diferença é de foco, de abrangência e de significado, ou seja, a Pedagogia realiza um filtro nas influências sociais que, em totalidade, atuam sobre uma geração. Essa filtragem é estabelecida por instituições sociais com fins educativos: a família, a igreja e, mais especificamente, a escola. Pode-se dizer que a igreja ainda exerce influência pedagógica na subjetividade da estrutura pedagógica de uma sociedade. Esta filtragem, que é o mecanismo utilizado pela ação pedagógica, é na realidade um processo de regulação e, como tal, um processo educativo.

Reitero, assim, o sentido de Pedagogia como prática social, oferecendo uma direção de sentido às práticas que ocorrem na sociedade, realçando seu caráter eminentemente político. Ela impõe/propõe/indica uma direção de sentido. Nessa perspectiva, processos vinculados a mídias como TV, redes sociais online, internet, passam a ter, neste atual século, grande influência educacional sobre as novas gerações, competindo com as escolas em desigualdade de condições. A escola e suas práticas pedagógicas têm tido dificuldades em mediar e potencializar as tecnologias da informação e comunicação. O que/como pode a Pedagogia mediar tais influências? Como transformá-las em processos pedagógicos numa perspectiva emancipadora? Um dos temas cruciais da Pedagogia, como educar/formar mediando tantas influências educacionais, nos alerta para a complexidade das práticas pedagógicas e para a docência: como trazer à escola essa multiplicidade de influências e trabalhar pedagogicamente a partir delas?

A escola sozinha não faz milagres! Numa sociedade excludente, a escola pode oferecer alguns instrumentos para conscientizar o sujeito do espaço social que cada um ocupa. Só um sujeito consciente e crítico pode tensionar em alguns momentos a realidade social estruturada. Mas a escola é fundamental na formação de sujeitos críticos, aqueles que podem produzir rupturas no já estabelecido.

O que são, afinal, práticas pedagógicas? Como mobilizá-las a favor de um projeto de inclusão social/política/afetiva?

Práticas pedagógicas são práticas que se organizam intencionalmente para atender determinadas expectativas educacionais solicitadas/requeridas por uma dada comunidade social. Nesse sentido, elas enfrentam, em sua construção, um dilema essencial: sua representatividade e seu valor advêm de pactos sociais, de negociações e deliberações com um coletivo. Ou seja, as práticas pedagógicas se organizam e se 
desenvolvem por adesão, por negociação, ou ainda, por imposição. Por certo, essas formas de concretização das práticas produziram faces diferentes para a perspectiva científica da Pedagogia! ${ }^{3}$

Considero que as práticas pedagógicas se constituem por um conjunto complexo e multifatorial de mediações sociais. Devido ao fato de as práticas pedagógicas se "infiltrarem" na cultura de modo a assegurar sua legitimação e, também, por se aninharem em práticas já existentes, elas requerem adesão, negociação e, em alguns casos, imposição; conforme já mencionado. Por exemplo, a obrigatoriedade de encaminhar crianças à escola ocorre, na maioria dos casos por adesão, mas ocorre, também, por imposição. A escolha, pelos pais, de determinadas escolas em detrimento de outras, deve-se à decisões deste tipo: alguns preferem colocar a criança na escola $\mathrm{X}$, porque lá a alfabetização inicia-se logo depois dos 4 anos de idade; outros preferem a escola Y, onde a alfabetização é tardia em relação à anterior. Em muitos casos trata-se de adesão à alguma proposta pedagógica, mas envolve negociações e acertos mútuos.

A camada mais desfavorecida socialmente, não possui opções. Cabe-lhes à escola pública, nas proximidades de seu local de residência. Por isso sempre exalto uma fala importante do pesquisador português Antônio Nóvoa: é na escola pública, através dela, que um país ganha ou perde seu futuro. E mais adiante comenta: Os brasileiros já incorporaram a ideia de que a escola é importante e de que é preciso que as crianças a frequentem. Mas ainda não há um verdadeiro compromisso com essa ideia. Não falo apenas numa escola onde todas as crianças estejam, mas onde todas as crianças aprendam ${ }^{4}$.

O compromisso de quem fala, significa um verdadeiro pacto para a educação de todos, o que se pode fazer através da escola pública. Decisões, princípios, ideologias, estratégias de negociação e adesão, são ingredientes estruturantes das práticas pedagógicas. Tais práticas precisam ser percebidas, analisadas e compreendidas na perspectiva da totalidade. Desse modo, nos processos coletivos de tomada de decisão da escola, as práticas pedagógicas precisam ser explicitadas em sua intencionalidade. Práticas pedagógicas impostas sem tais explicitações, tendem a ser superficialmente absorvidas, sem adesão do grupo que as protagoniza.

${ }^{3}$ Para aprofundar essa questão vide: FRANCO, Maria Amélia Santoro. A pedagogia como ciência da educação: entre epistemologia e prática. Tese de doutoramento. USP. São Paulo. 2001.

${ }^{4}$ JORNAL ATARDE., 25/07/2016 às 10:59|. Atualizado em: 25/07/2016 às 12:36. 
Há outros ingredientes da complexidade das práticas pedagógicas. Há, por exemplo, uma história das práticas, culturalmente e socialmente engendradas, o que produz expectativas de papel e representações sociais variadas. Como se sabe, historicamente, o Brasil viveu a dualidade de práticas escolares: algumas práticas são convenientes só para elite; outras para a educação popular! Isso continuamente excluiu os menos favorecidos de processos de verdadeira inclusão social!

Há uma história da profissão, do papel social do professor, o que delimita poderes e perspectivas no exercício do ser e estar na profissão. Nesse cenário de tantas práticas e culturas aninhadas, que criam e criaram um ethos profissional, como mudar as práticas por imposição? Como dizer que doravante a profissão professor perderá uma instância essencial de sua atividade que é ensinar, avaliar, replanejar? Em políticas educacionais de alguns estados brasileiros, principalmente aquelas orientadas por propostas neoliberais, o deliberar sobre princípios, métodos, perspectivas e intencionalidades do processo de avaliação da aprendizagem passa a não ser mais da competência do docente, nem do coletivo dos docentes, nem das orientações das teorias pedagógicas; outros interesses, não explícitos, comandam a organização de novas práticas pedagógicas.

Assim quero realçar o papel relativo das escolas na construção de práticas escolares includentes numa sociedade de enormes diferenças sociais como a sociedade brasileira. O que pode a escola frente à sujeitos tão excluídos? Ela, a escola, pode muito, e precisa fazer valer essa possibilidade.

Disse acima que as práticas pedagógicas são práticas sociais que se organizam para dar conta de determinadas expectativas educacionais de um grupo social. Duas questões se mostram fundamentais: articulação com as expectativas do grupo e a existência de um coletivo. Refiro-me ao fato de que as práticas pedagógicas só podem ser compreendidas na perspectiva da totalidade, ou seja, as práticas pedagógicas e práticas docentes estruturam-se em relações dialéticas pautadas nas mediações entre totalidade e particularidade.

Quando realço a categoria totalidade como marcante e essencial ao sentido de prática pedagógica, quero entendê-la como expressão de um dado momento/espaço histórico, permeada pelas relações de produção, relações culturais, sociais e ideológicas. Desse modo, como prática social, a prática pedagógica produz uma dinâmica social entre o dentro e o fora (dentrofora) da escola. Isto significa que o professor sozinho não 
transforma a sala de aula, que as práticas pedagógicas funcionam como espaço de diálogo: ressonância e reverberação, das mediações entre sociedade e sala de aula.

A sala de aula é um espaço onde acorrem as múltiplas determinações decorrentes da cadeia de práticas pedagógicas que a circundam. Quando se considera a necessidade de olhar essas práticas na perspectiva da totalidade, compreende-se melhor essas relações, tal como realça Lukács (1967, p. 240):

\begin{abstract}
A categoria de totalidade significa [...] de um lado, que a realidade objetiva é um todo coerente em que cada elemento está, de uma maneira ou de outra, em relação com cada elemento e, de outro lado, que essas relações formam, na própria realidade objetiva, correlações concretas, conjuntos, unidades, ligados entre si de maneiras completamente diversas, mas sempre determinadas [...]
\end{abstract}

Este todo é composto de partes, leis, lógicas mediadas entre si e, quando se desconectam, produzem desarticulações que prejudicam o sentido original que possuíam. Desse modo, não é da natureza das práticas docentes encontrarem-se avulsas, desconectadas de um todo, sem o fundamento das práticas pedagógicas que lhe dão sentido e direção. A prática docente avulsa, sem ligação com o todo, perde o sentido. É esta uma das razões que justifica a presença da de um projeto político pedagógico, real e construído pelo coletivo nas escolas, que tem por finalidade explicitar as finalidades do trabalho pedagógico, organizar espaços e possibilidades de conexão, de articulação, de sentido, entre a prática docente e a prática pedagógica.

No projeto político pedagógico de uma escola, devem estar expressos as expectativas e intenções do grupo escola. Nesse projeto, amalgamam-se práticas pedagógicas circundantes; a cultura da comunidade, os conhecimentos que devem fazer parte do conhecimento escolar e assim, surgem novas práticas que lhe darão sustentação. Tornar vivo a cada dia o projeto pedagógico é fundamental para a circulação de sentidos e envolvimento coletivo do grupo de professores e equipe pedagógica.

O projeto pedagógico elaborado apenas pela equipe dirigente ou que fica só no papel, de nada serve. Ele precisa expressar os anseios e expectativas do grupo envolvido com aquela escola. Não há projeto pronto, não há práticas prontas. As práticas pedagógicas deverão se reorganizar e se recriar a cada dia para dar conta do projeto inicial que vai transmudando-se à medida que a vida, o cotidiano e a existência o invadem. Há uma “insustentável leveza” das práticas pedagógicas que permite a 
presença de processos que organizam comportamentos de adaptação/renovação decorrentes das transformações inexoráveis que vão surgindo nas múltiplas mediações/superações entre mundo e vida.

Uma escola inclusiva requer um ativo e dialogante projeto pedagógico que vai se ajustando e se retificando com as práticas vividas. A prática pedagógica crítica é um motor das contínuas inclusões de cada aluno, de cada docente, de cada expectativa nas práticas escolares.

A educação, especialmente a educação escolar, deve ser o instrumento por excelência da humanização dos homens em sua convivência social, uma vez que os sujeitos, imersos em sua prática e impregnados das diversas influências educacionais, estão constantemente participando, interagindo, intervindo no seu próprio contexto cultural, requalificando a civilização, para condições que deveriam ser cada vez mais emancipatórias e humanizantes. Como realça Charlot:

O sujeito se constrói pela apropriação de um patrimônio humano, pela mediação do outro, e a história do sujeito é também a das formas de atividade e de tipos de objetos suscetíveis de satisfazerem o desejo, de produzirem prazer, de fazerem sentido. (2005, p. 38)

O pedagógico é, neste sentido, um elemento relacional entre os sujeitos, portanto, o pedagógico é uma construção coletiva, não existe a priori, não existe senão na dialogicidade dos sujeitos da educação, conforme a visão de Freire. Percebe-se facilmente que o potencial educacional de uma sociedade pode ou não ser uma influência educativa. Dependerá de como tais ações e práticas se organizam com os projetos sociais de formação, de humanização dos sujeitos.

Portanto, a prática pedagógica realiza-se através de sua ação científica sobre a práxis educativa, visando compreendê-la, torná-la explícita à seus protagonistas, transformá-la, através de um processo de conscientização de seus participantes, dar-lhe suporte teórico; teorizar, com os atores, buscar encontrar em sua ação o conteúdo não expresso de suas práticas. Como enfatiza Veiga (1992, p. 117):

Na sala de aula, o professor faz o que sabe, o que sente e se posiciona quanto à concepção de sociedade, de homem, de educação, de escola, de aluno e de seu próprio papel. [...] é na sala de aula que o professor cria e recria as possibilidades de sua prática docente, toma decisões, revê seus procedimentos, avalia o que fez. 
Ou seja, o professor, ao construir sua prática pedagógica, está em contínuo processo de diálogo com o que faz, porque faz e como deve fazer. É quase que intuitivo esse movimento de olhar, avaliar, refazer. Construir e desconstruir; começar de novo; acompanhar e buscar novos meios e possibilidades. Essa dinâmica é o que faz da prática, uma prática pedagógica.

\section{Práticas de inclusão e acolhimento}

Parece que já deixei esclarecido neste texto que a inclusão é um processo para além do acolhimento. Prevê o acolhimento, mas o supera. As práticas de acolhimento confortam, mas nem sempre permitem a superação das condições e dos sentimentos de exclusão. No acolhimento há um movimento de fora para dentro: os outros recebem o excluído, confortam-no; no entanto é preciso mais que isso; é preciso formar neste sujeito as possibilidades de superação de suas necessidades; nas práticas de inclusão devolve-se ao sujeito suas possibilidades de ser sujeito autônomo, é um processo de formação e de desenvolvimento da consciência crítica, na perspectiva proposta por Freire quando explicita a necessária superação da consciência ingênua. ${ }^{5}$

Pedagogicamente, afirmamos que:

- Todos precisamos de inclusão e acolhimento.

- Todos somos especiais! De diferentes maneiras.... possibilidades....

- Por isso precisamos da Pedagogia: através dela ajustamos necessidades e

Para isso precisamos de condições para a Pedagogia atuar. Assim, decorre da epistemologia pedagógica que as escolas precisam de novas formas de organização; novos tempos para formação; a contínua prática de processos dialógicos e reflexivos; além de espaços para práticas coletivas, num ambiente em que o professor se sinta dignamente considerado em suas atividades e processos de profissionalização. Esta reflexividade e politicidade é a base da racionalidade pedagógica, racionalidade esta incompatível com a prática de uma educação neutra, meramente tecnicista e burocraticamente conduzida. O tecnicismo esmaga esta racionalidade! Ou como se expressa Gentile:

O neoliberalismo precisa - em primeiro lugar, ainda que não unicamente - despolitizar a educação, dando-lhe um novo significado como mercadoria para garantir, assim, o triunfo de suas estratégias

${ }^{5}$ In: FREIRE. Pedagogia do oprimido. 
mercantilizantes e o necessário consenso em torno delas" (1995, p. 244-245).

O mundo pedagógico parece estar sendo varrido do mundo educacional, de forma a abrir espaços para a circulação da lógica transmissiva e supostamente neutra de informações superficiais e anômalas e de um praticismo sem teoria, o que gera um quadro de exercício de ações sem significado, rebatendo na despersonalização da docência. Essas circunstâncias são aquelas que excluem pessoas, excluem alunos; excluem esperanças! É dessa racionalidade que fala Freire ao realçar que:

\begin{abstract}
A compreensão dos limites da prática educativa demanda indiscutivelmente a claridade política dos educadores com relação a seu projeto. Demanda que o educador assuma a política de sua prática. Não basta dizer que a educação é um ato político, assim como não basta dizer que o acto político é também educativo. É preciso assumir realmente a política da educação. (FREIRE, 1993, p. 46-47).
\end{abstract}

Portanto o processo de inclusão começa na boa formação docente, para que este, de posse de práticas e teorias pedagógicas adequadas possa reivindicar espaços e tempos necessários ao processo de inclusão. Nenhum professor trabalha bem, pedagogicamente falando, sem as condições institucionais e políticas adequadas. Lembro-me da fala de uma professora da Educação de Jovens e Adultos, numa prefeitura da Baixada Santista: esses alunos já foram excluídos a vida toda e hoje quero bem trabalhar com eles, mas não há sala apropriada; não há tempo suficiente, nem estímulos ao meu trabalho. Somos ambos, alunos e professores, excluídos!

A prática pedagógica bem vivida e bem organizada é o fundamental fator para o exercício crítico e poderoso da inclusão de cada um como cidadão e sujeito social.

\title{
Considerações finais
}

Em conversa com Bernard Charlot o mesmo me pergunta:

- $\quad$ Como construir uma pedagogia em uma sociedade que deixou esmorecer a questão dos valores?

- $\quad$ Como construir uma pedagogia em uma sociedade que não sabe mais dizer aos jovens o que vale a pena (exceto consumir e passar no vestibular)?

- $\quad$ Como construir uma pedagogia em uma sociedade em que os indivíduos são cada vez mais livres e os sujeitos cada vez mais abandonados?

- $\quad$ Como construir novas solidariedades? 
Paulo Freire mantém a mesma indignação ao referir-se à escuta como um dos instrumentos da prática do diálogo pedagógico:

Aceitar e respeitar a diferença é uma dessas virtudes sem o que a escuta não se pode dar. Se discrimino o menino ou a menina pobre, a menina ou o menino negro, o menino índio, a menina rica; se discrimino a mulher, a camponesa, a operária, não posso evidentemente escutá-las e se não as escuto, não posso falar com eles, mas a eles, de cima para baixo. Sobretudo, me pró́bo entendê-los. Se me sinto superior ao diferente, não importa quem seja, recuso-me escutá-lo ou escutá-la.

A boa formação pedagógica permite ao professor ser um bom "escutador" do outro e permite-lhe também tecer alternativas de práticas que podem produzir novos significados àqueles tão excluídos socialmente. $\mathrm{O}$ professor(a) atento pedagogicamente a seus alunos devem estar vigilantes às suas especificidades; reparando e lendo o significado em seus corpos, em suas perguntas em seus silêncios. O professor que inclui saberá significar e identificar em seus alunos:

- $\quad$ À inquietação dos seus corpos;

- $\quad$ Os olhares surpresos ou entediantes;

- $\quad$ As reações agressivas ou excessivamente apáticas;

- Os comportamentos tímidos ou distanciados;

E frente à essas especificidades o professor saberá observar/escutar/ouvir/dialogar; e exercer práticas articuladas à novos sentidos e novas aspirações. Essa é a rebeldia pedagógica: transformar apatias em novos sentidos; incluir os apáticos e rebeldes; oferecer novas dimensões para olhar a vida e criar novos sentidos. E chamamos Freire para nos encorajar:

Não é na resignação, mas na rebeldia em face das injustiças que nos afirmamos. Uma das questões centrais com que temos de lidar é a promoção de posturas revolucionárias que nos engajam no processo radical de transformação do mundo. A rebeldia é ponto de partida indispensável, é deflagração da justa ira, mas não suficiente. A rebeldia enquanto denúncia precisa se alongar até uma posição mais radical e crítica, a revolucionária, fundamentalmente anunciadora. A mudança do mundo implica a dialetização entre a denúncia da situação desumanizante e o anúncio de sua superação, no fundo, o nosso sonho. (FREIRE, 1996, p. 87-88) 
O pedagógico é a dinâmica da escola, da educação, dos múltiplos ensinos, por isso mesmo, é resultante da colaboração de todos, nos diversos espaços e tempos do ambiente e da convivência escolar...

"Numa sociedade de relações contraditórias, excludentes, desiguais, opressivas, a Pedagogia há que se fazer emancipatória, pois só conseguiremos mais humanidade nos homens à medida que haja a transformação das condições que produzem exclusão/opressão" (Schmied- Kowarsik)

\section{REFERÊNCIAS}

CHARLOT, B. Relação com o saber, formação de professores e globalização: questões para a educação hoje. Porto Alegre: Artmed, 2005.

CONTRERAS, J. La investigación en la acción. Cuadernos de Pedagogía, Barcelona, abr. 1994, p.7-19.

FRANCO, M. A. S. A Pedagogia como ciência da educação: entre práxis e epistemologia. Tese de doutoramento. Universidade de São Paulo. São Paulo. 2001.

FRANCO, M. A. S. Pedagogia e prática docente. São Paulo: Cortez Editores, 2012.

FRANCO, M. A. S. Práticas Pedagógicas nas múltiplas redes sociais. In: LIBÂNEO, J. C.; ALVES, N. Doze temas da pedagogia: as contribuições do pensamento em currículo e em didática. $1^{\text {a }}$ ed. São Paulo: Cortez Editores, 2012a, v.1, p. 169-189.

FREIRE, P. Pedagogia da autonomia: saberes necessários à prática educativa. São Paulo: Paz e Terra, 1999.

FREIRE, P. Política e educação. São Paulo: Cortez Editores,1993.

FREIRE, P. A educação como prática da liberdade. Rio de Janeiro: Paz e Terra, 1976.

FREIRE, P. A Pedagogia do oprimido. Rio de Janeiro: Paz e Terra, 1975.

FREIRE, P. Cartas a Cristina. São Paulo. Paz e terra. Rio de Janeiro. 1996.

GENTILI, P. A. A. O discurso da "qualidade" como nova retórica conservadora, no campo educacional. In: GENTILI, P. A. A.; SILVA, T. T. (Org.). Neoliberalismo, qualidade total e educação. 2. ed. Petrópolis: Vozes, 1995.

LUKÁCS, G. Existencialismo ou marxismo. São Paulo: Senzala, 1967. 
NÒVOA, A. Entrevista. Disponível em:

$<$ http://www.cartaeducacao.com.br/entrevistas/antonio-novoa-aprendizagem-nao-esaber-muito/>. Acesso em: 20 jul. 2016.

PACHECO, J. Aula não ensina, prova não avalia.

<https://www.youtube.com/watch?v=rcH8YXGDeB8>. Acesso em:21 jul. 2017.

SCHMIED-KOWARZIK, W. Pedagogia Dialética - de Aristóteles a Paulo Freire.São Paulo: Brasiliense, 1983.

VEIGA, I. P A. A prática pedagógica do professor de didática. 2 ed. Campinas: Papirus, 1992

\section{Como referenciar este artigo}

FRANCO, Maria Amélia Santoro. Práticas pedagógicas de acolhimento e inclusão: a perspectiva da pedagogia critica. Revista on line de Política e Gestão Educacional, Araraquara, v. 21, n. esp. 02, p. 964-978, nov. 2017. Disponível em: <http://dx.doi.org/10.22633/rpge.v21.n.esp2.2017.10370>. E-ISSN:1519-9029.

Submetido em: 05/09/2017

Aprovado em: 21/09/2017 